\title{
commentary
}

\section{Learning from students at Lindau}

\author{
Martin Chalfie
}

\section{Each year since 1951, young researchers and Nobel Laureates have gathered on the shores of Lake Constance for a unique scientific conference. In 2009 the meeting was dedicated to chemistry, and Laureates and students all came away enriched by their experiences.}

$\mathrm{B}=$ eing awarded a Nobel Prize has many unforeseen consequences. In the ten months since last October's announcement of my sharing the chemistry prize, I was made a topic in the art show of the biennial C. elegans meeting; I was asked for autographs from people who do not seem to know my name, but who nonetheless said they had been fans of my work for many years; and I received invitations, including two from heads of state, to attend and speak at numerous meetings on topics I know nothing about. One of the nicest consequences, however, was being asked to participate in this year's Lindau Nobel Laureate meeting.

The original meeting in 1951 arose from a suggestion from two physicians, Gustav Parade and Franz Karl Hein, to Count Lennart Bernadotte, that German medical students should have an opportunity to meet the Nobel Laureates in Medicine or Physiology. The Lindau Nobel Laureate meetings have since expanded and evolved so that now the Lindau Foundation, currently headed by Countess Bettina Bernadotte, invites some of the most exciting young researchers from all over the world (most are graduate students) and a large contingent of Laureates, and lets them interact. Usually the meetings are organized around thematic areas recognized by the Nobel Prize (Medicine/Physiology, Chemistry, Physics or Economics). Additionally, a few of the meetings have been interdisciplinary. This year's meeting, the 59th, was held from 28 June to 3 July and brought together approximately 600 young researchers and 23 laureates in the field of chemistry.

Most of the sessions occur at the conference centre on the German island of Lindau situated in Lake Constance. On the final day of the meeting, however, the participants take a beautiful boat ride to the island of Mainau, the home of the

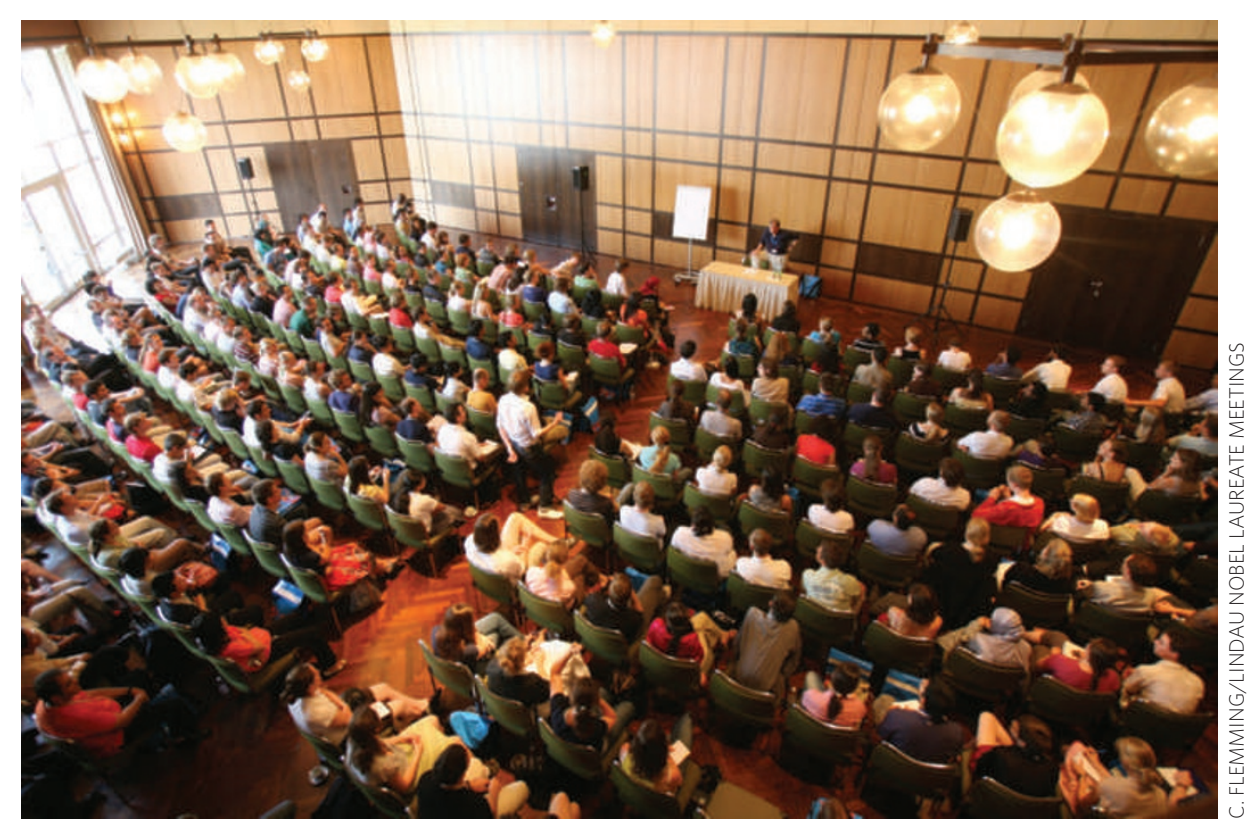

After the formalities of morning lectures at the Lindau meeting, afternoons were set aside for discussions between the young researchers and the Laureates.

Bernadottes, for the final discussion and closing ceremonies. Lindau and Mainau are wonderful places to visit, and the meeting facilities are excellent. And the cities go all out for the meeting. Large banners showing the faces of the Laureates are prominently displayed on the main road going into Lindau. These black-and-white photographs by Peter Badge also decorate the conference centre. I am not sure that any other city displays pictures of scientists for all to see (although this may not be a bad idea). In any case, they certainly take their Laureates seriously in Lindau.

The wonderful Bavarian setting - even with the scientist banners - is not, however, what makes these meetings so enjoyable and worthwhile. The scientific discussions are the high points of the meetings. As the event this summer was the first I attended, I was very interested in meeting and talking with my fellow Laureates, most of whom I had not known previously. I, as much as the students, wanted to hear what they had to say. And they did not disappoint.

Some described the work for which they had received the prize, others talked about the directions that their work had taken since the prize or about general scientific trends that intrigued them, and still others talked about interests and preoccupations outside of their research. In all, the Laureates talked about their passions, and they were, not surprisingly, quite varied. For example, Osamu Shimomura (Chemistry, 2008) spoke about the wide variety of mechanisms underlying bioluminescence in nature, Mario Molina (Chemistry, 1995) 
about energy and climate change, and Richard Ernst (Chemistry, 1991) about his love for Himalayan art.

As informative and thought provoking as these lectures were, the real high points of the meeting, to me, were the discussions with the students. During the afternoon sessions, the Laureates who had already given their talks that morning were installed individually in rooms where students could ask them questions. No one else was admitted. My session lasted for two hours. I had spoken with students before my presentation, but usually the interactions were general (pictures, autographs, finding out superficially about them and their interests). After my talk, the students knew what my current interests were and the discussions went in all sorts of interesting directions.

Some asked about my career path (checkered) and others wondered if I had any advice (not really). Most of the questions, however, were about the science. From their reading or from simply listening to my talk, the students generated a large number of fascinating questions. They wanted to know details of the experiments and they wanted to discuss potential future experiments. Conclusions about my research that had taken me years to realize (and which I have not written about or described in my talk) were instantly suggested by several of the students at the session. Seeing their excitement and quickness was humbling, but also invigorating. These conversations about the work continued through to the end of the meeting (including on the trip to Mainau), and I was impressed by how intelligent and interested the students were. I wanted all of them to come to my lab.

\section{As informative and thought provoking as these lectures were, the real high points of the meeting, to me, were the discussions with the students.}

I had a wonderful time at the meeting, but what about the students - what did the meeting offer them? First, the meeting allowed the students (as well as the Laureates) to broaden their horizons, to have a chance to meet, exchange ideas, and learn about new areas of research from investigators from all over the world (the conference participants came from 67 different countries). The word 'exchange' is important here, because I don't believe that the real benefits were associated with hearing advice from a bunch of older scientists who had been fortunate enough to get some recognition for their work. After all, the students had probably gotten as good, if not better, advice from their own mentors and other investigators at their home institutions.

The second benefit of being chosen to attend these meetings, I think, is the acknowledgement it gives to young scientists, especially at a time when they do not get much recognition, that they are on their way to succeeding in science, and that we think that they are important. Although they really do not need any seal of approval, everyone likes to get the occasional pat on the back. The Lindau Nobel Laureate meetings do a terrific job of giving that pat on the back.

I have been invited to the multidisciplinary meeting next year. I will definitely attend, and I have already requested that my talk be early in the session, so I can have even more time with the students. I feel fortunate to be part of the discussions.

Martin Chalfie was one of the three recipients of the 2008 Nobel Prize in Chemistry, and is in the Department of Biological Sciences, Columbia University, New York, New York 10027, USA. e-mail:mc21@columbia.edu

\title{
Looking back on Lindau
}

\author{
Jeffrey R. Lancaster
}

\section{The Nobel Laureate Meetings held on the German island of Lindau bring together some of the world's brightest young minds with those individuals who have reached a pinnacle of scientific achievement. The impact of this unique event on all the delegates - especially the young researchers - is far-reaching.}

W hen I stepped off the bus in Lindau, I fully expected to be part of a unique conference boasting an extraordinary proportion of attendees who have been awarded the Nobel Prize, and I was not disappointed. The list of Nobel Laureates scheduled to attend was posted well in advance of the conference, and even the topics on which the Laureates would speak was already known ${ }^{1}$. In this sense, there were few surprises to be had. What did catch me off guard, however, was that my experiences in Lindau were most strongly shaped by my peers - young researchers - followed closely by my interaction with members of the media and the conference support staff.
For a summer in which I attended four important conferences, the Lindau meeting doesn't, surprisingly, stand out as overtly special at first glance. Compared with these other events, the application process for the Lindau event was merely lengthier, but the fundamental principles behind the Lindau meeting were the same as for any other disciplinary seminar, namely to encourage conversation among scientists and to showcase relevant scientific research. However, two subtle points have ultimately distinguished the Lindau meeting for me as a unique event of which I was honoured to have been a part.

First, conversation and the sharing of ideas were fostered not solely between scientists with comparable levels of experience, but also across scientific generations and geographies. I had worthwhile discussions with my peers from Australia, China, India, the Netherlands, Poland and Spain (to name but a few), and was able to speak to scientists at various stages of their careers, from undergraduate to graduate students, postdocs, professors, governmental scientists and, of course, Nobel Laureates. Second, the activities pursued by scientists outside of publishable, academic research also featured prominently at the meeting. That scientists might have a life apart from, and in addition to, their research is most often a topic best reserved for conference 